\title{
Comparative study between microdebrider, radiofrequency and classic microlaryngosurgical in the treatment of benign vocal cord lesions

\author{
Mahmoud Ashraf Ragab ${ }^{a}$, Elham A. Shahin ${ }^{a}$, Ahmed M. Atef ${ }^{a}$, Hany Samir ${ }^{b}$, \\ Mohammed A. Hussein ${ }^{b}$
}

${ }^{a}$ Department of Otorhinolaryngology, Cairo University, Giza, 'Department of

Otorhinolaryngology, Fayoum University,

Fayoum, Egypt

Correspondence to Hany Samir, MD,

Department of Otorhinolaryngology Fayoum

University, Fayoum, 730816, Egypt.

Tel: +20 100178 9647; fax: +201111000114

e-mail: hanysam2002@yahoo.com

Received 27 October 2016

Accepted 27 December 2016

The Egyptian Journal of Otolaryngology 2018, 34:179-190

\author{
Background \\ Benign vocal fold lesions are a common cause for hoarseness of voice. \\ Aim \\ The aim of this work was to investigate the efficacy and safety of microdebrider and \\ radiofrequency in excision of benign vocal fold lesions compared with the classic \\ microlaryngosurgical (MLS). \\ Patients and methods \\ This study included 30 patients, 22 male and eight female, diagnosed to have \\ benign vocal fold lesions, who were divided into three groups: \\ They were assessed preoperatively and 2 weeks postoperatively using the GRB \\ scale for auditory perceptual assessment and computerized speech lab. \\ Results \\ Marked improvement of vocal functions with no statistically significant differences \\ between the three groups was observed. \\ Conclusion \\ Radiofrequency and microdebrider could be used in the treatment of benign vocal \\ fold lesions with nearly the same results of MLS. \\ Keywords: \\ benign vocal fold lesions, microdebrider, microlaryngosurgical, radiofrequency \\ Egypt J Otolaryngol 34:179-190 \\ (1) 2018 The Egyptian Journal of Otolaryngology \\ 1012-5574
}

\section{Introduction}

Benign glottic lesions are not a rare entity; they produce symptoms that vary from mild hoarseness of voice to life-threatening stridor, as it may be large enough to obstruct the airway. It has been noted that the vocal folds are especially prone to abuse due to atmospheric pollution, smoking, alcohol consumption, dust, fumes and misuse of voice. Over and above all these is the effect of recurrent upper and lower respiratory tract infection. Professional voice users, housewives and children form a group that is susceptible to the development of benign glottic lesions [1].

Benign superficial lesions of the vocal fold (nodule, polyp, Reinke's oedema and granulomas) arise from the epithelium and the lamina propria (LP). Vocal misuse and abuse lead to excessive mechanical stress and trauma in the membranous portion of the vocal fold, resulting in wound formation [2].

Wound healing leads to remodelling of the superficial layer of the LP and the vocal fold epithelium. This tissue remodelling leads to the formation of a benign vocal fold lesion. Several studies have demonstrated that the pathological changes in benign vocal fold lesions occur within the superficial layer of the LP [3].
Granulomas of the larynx can be classified into two general groups: specific granulomas and nonspecific granulomas. Specific granulomas are rare and include granulomas caused by tuberculosis, syphilis and laryngoscleroma, which is caused by Klebsiella rbinoscleromatis (Gram-negative encapsulated diplobacillus); contact granulomas are benign lesions usually located on the posterior third of the vocal fold, which corresponds to the vocal process of the arytenoid cartilage. Contact granulomas may occur unilaterally or bilaterally. Contact ulcers (or granulomas) historically were thought to be the result of voice abuse or misuse, and the granulomas of intubation or gastroesophageal reflux were separate subsets of these conditions. However, for all purposes, the appearance, symptomatology and treatment of these nonspecific granulomas are identical; therefore, both subsets of nonspecific granulomas can be considered a single entity [4].

Treatment options for benign vocal fold lesions include both invasive and noninvasive techniques. A simple

\footnotetext{
This is an open access journal, and articles are distributed under the terms of the Creative Commons Attribution-NonCommercial-ShareAlike 4.0 License, which allows others to remix, tweak, and build upon the work non-commercially, as long as appropriate credit is given and the new creations are licensed under the identical terms.
} 
superficial excision, sparing the underlying uninvolved LP and minimizing the epithelial loss, is generally sufficient. To accurately achieve these goals, however, high-powered binocular visualization and delicate microlaryngeal instrumentation is required [5].

Endoscopic removal of laryngeal and tracheal lesions is generally performed using laser technology or microlaryngeal instrumentation. The powered laryngeal shaver or microdebrider has provided an alternative to conventional endoscopic surgery and laser resection of most airway lesions [6].

Radiophonosurgery opens a new therapeutic approach for patients with benign superficial vocal fold lesions. It combines the advantages of both cold knife and laser phonosurgery, being easy, safe, precise and effective, and having excellent tactile and haemostatic properties [2].

\section{Patients and methods}

This study was a randomized comparative trial that included 30 patients, 22 male and eight female, who presented to the ENT outpatient clinics of Cairo University and Fayoum University hospitals and were diagnosed to have benign vocal fold lesions; their ages ranged between 13 and 37 years, and an informed consent for the procedure was obtained. Counselling including all reasonable vocal expectations, limitations and potential surgical complications was done. This study was carried out in the period between January 2014 to January 2015 and the ethical comities in Cairo University.

\section{Patients selection}

Patients were randomly selected regardless the age or sex and divided into three groups:

(1) Group A: 10 patients treated by the classic microlaryngosurgical (MLS) techniques.

(2) Group B: 10 patients treated by the laryngeal microdebrider.

(3) Group C: 10 patients treated by radiofrequency.

The exclusion criteria included pregnancy, significant psychological problems and unfit patients for general anaesthesia because of concurrent medical conditions.

\section{Patients' assessment}

All the patients were assessed preoperatively and 2 weeks postoperatively (after history taking and general examination) at the phoniatrics' unit by the following methods:

(1) Auditory perceptual assessment with a simplified version of the GRBAS scale (GRB) consisting of
G (grade), R (roughness) and B (breathiness) was performed.

(2) Laryngoscopic examination: either flexible or rigid laryngoscopic examination and video documentation of preoperative postoperative findings was performed for accurate record keeping, as well as for medicolegal importance.

(3) Acoustic analysis using computerized speech lab. (CSL) was performed to assess perturbation of frequency and amplitude (jitter and shimmer, respectively), noise to harmonic ratio, fundamental frequency FO and highest and lowest FO.

\section{Operative procedure}

All procedures were performed under general anaesthesia with the smallest and safest endotracheal tube, and all cases were examined using a direct laryngoscope (DL) and kAPS operating microscope (DP Medical systems 15A 0akcroft).

The same surgical principles were applied in MLS and radiofrequency for excision of vocal fold lesions, which were grasped with a fine forceps and excised at their base using cold instruments in MLS or the laryngeal blade of radiofrequency (Fig. 1).

The radiofrequency device model used in this study was 'Arthrocare ENT coblator II' (Smith and Nephew Surgical devices 150 minuteman Rd.), and the power was adjusted to the seventh grade for ablation and excision of the lesion and the fourth grade for coagulation when needed for homoeostasis.

Laryngeal microdebrider was applied directly to the lesion, which is excised and sucked by the attached suction device.

We used Bien Air device (Rue de 1 Quest, le Noirmont, Switzerland) with speed set at $500 \mathrm{rpm}$ using the round window blade.

Excessive redundant mucosa was then grasped and trimmed usually using cold instruments without injury of the underlying vocal ligament (Fig. 2).

Haemostasis was usually secured using cotton pledgets soaked with adrenaline 1/200 000 solution. All

\section{Figure 1}

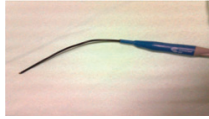

Laryngeal blade of radiofrequency used in this study. 
specimens were sent for histopathological examination and were consistent with the diagnosis of benign vocal fold lesions.

\section{Postoperative care}

The recommended postoperative care was as follows:

A policy of 2 days of complete voice rest, followed by 2 weeks of voice moderation, was applied.

(1) Smoking was prohibited for at least 2 weeks after surgery.

(2) Postoperative voice therapy was provided for all patients, and hydration and humidification were advised.

(3) Complications, smoothness of postoperative recovery and administration of analgesia were reported.

\section{Statistical analysis}

The collected data were organized, tabulated and statistically analysed using SPSS software statistical computer package (version 19; SPSS Inc., Chicago, Illinois, USA). For quantitative data, the mean \pm SD were calculated. Analysis of variance was used to test the difference about mean values of measured parameters among the three groups. Paired $t$-test was used in comparison between the difference of parameters before and after intervention. For qualitative data, the number and per cent distribution were calculated, and $\chi^{2}$ was used as a test of significance. For interpretation of results of tests of significance, significance was adopted at $P$-value less than 0.05 and was highly significant at $P$-value less than 0.001 .

\section{Results}

This study was conducted on 30 patients (aged between 13 and 37 years old, with a mean \pm SD age of around $25 \pm 3$ years) who were diagnosed to have benign vocal

\section{Figure 2}

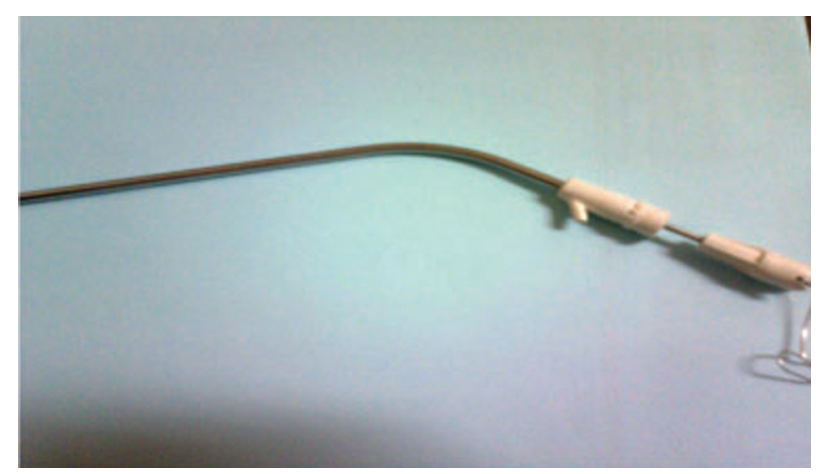

Laryngeal blade of microdebrider used in this study. fold lesions and presented with persistent hoarseness of voice for more than 2 months.

Patients were divided randomly into three groups as follows:

(1) Group A (10 patients) underwent DL and excision using MLS techniques (cold knife).

(2) Group B (10 patients) underwent DL and excision using laryngeal microdebrider.

(3) Group C (10 patients) underwent DL and excision using radiofrequency.

In this study, males were seen to predominate over females; Table 1 indicates that, of these patients, 22 were male patients and eight were female patients.

Types of benign lesions included in this study are as follows:

(1) Twenty-five patients with unilateral vocal fold polyp.

(2) One patient with bilateral vocal fold polyps.

(3) One patient with vocal fold cyst.

(4) One patient with juvenile multiple papillomatosis.

(5) One patient with intubation granuloma.

(6) One patient with vocal fold polyp diagnosed histopathologically as laryngoscleroma.

\section{Preoperative assessment}

All patients were assessed preoperatively at the phoniatrics' unit by the following methods:

(1) Auditory perceptual assessment with a simplified version of the GRBAS scale (GRB) consisting of $\mathrm{G}$ (grade), R (roughness) and B (breathiness) was performed.

(a) All patients had dysphonia ranging from grade 2 to grade 3 .

(b) All patients had a rough voice (preoperatively).

(c) All patients of groups B and C had a breathy voice (pre operatively); on the other hand, only $60 \%$ of group A had a breathy voice (preoperatively).

Table 1 Comparison between the three groups regarding sex

\begin{tabular}{lcccc}
\hline Sex & \multicolumn{3}{c}{ Groups $[n(\%)]$} & Total \\
\cline { 2 - 4 } & Coblation & Microdebrider & MLS & \\
\hline Male & $7(70.0)$ & $6(60.0)$ & $9(90.0)$ & $22(73.3)$ \\
Female & $3(30.0)$ & $4(40.0)$ & $1(10.0)$ & $8(26.7)$ \\
Total & $10(100.0)$ & $10(100.0)$ & $10(100.0)$ & $30(100.0)$ \\
\hline
\end{tabular}

MLS, microlaryngosurgical. $P<0.05$, significant. $P=0.303$. 
Table 2 Comparison between the three groups regarding the degree of dysphonia (preoperatively)

\begin{tabular}{lcccc}
\hline Grade (preoperatively) & \multicolumn{3}{c}{ Groups $[n(\%)]$} & \multirow{2}{*}{ Total } \\
\cline { 2 - 4 } & Coblation & Microdebrider & $2(20.0)$ & $5(16.7)$ \\
\hline 2 & $1(10.0)$ & $2(20.0)$ & $8(80.0)$ & $25(83.3)$ \\
3 & $9(90.0)$ & $8(80.0)$ & $10(100.0)$ & $30(100.0)$ \\
\hline
\end{tabular}

MLS, microlaryngosurgical. $P=0.787 . P<0.05$, significant.

(2) Laryngoscopic examination, either rigid or flexible, was performed for diagnosis and documentation (video recording).

(3) Acoustic analysis was performed using CSL to assess perturbation of frequency and amplitude (jitter and shimmer, respectively), noise to harmonic ratio, fundamental frequency $\mathrm{FO}$ and highest and lowest FO.

Tables 3-5 show the statistical analysis of these preoperative values, and the significant statistical differences with no highly significant statistical differences $(P>0.001)$.

\section{Postoperative assessment}

All patients were assessed (2 weeks) postoperatively using the following methods:

(1) Laryngoscopic examination, either rigid or flexible, was performed for documentation (video recorded) and follow-up.

(2) Auditory perceptual assessment with a simplified version of the GRBAS scale (GRB) only was used in this study consisting of $\mathrm{G}$ (grade), $\mathrm{R}$ (roughness) and B (breathiness).

G: all the patients showed improvement of the grade of dysphonia as follows:

(1) Group A: microlaryngosurgical

(a) $40 \%$ of patients of this group reached grade 0 dysphonia.

(b) $60 \%$ of patients of this group reached grade 1 dysphonia.

(2) Group B: microdebrider
(a) $50 \%$ of patients of this group reached grade 0 dysphonia.
(b) $50 \%$ of patients of this group reached grade 1 dysphonia.

(3) Group C: coblation
(a) $50 \%$ of patients of this group reached grade 0 dysphonia.
(b) $40 \%$ of patients of this group reached grade 1 dysphonia.
(c) $10 \%$ (one patient) of patients of this group reached grade 2 dysphonia.

$\mathrm{R}$ : all the patients showed improvement of roughness:
Table 3 Comparison between the three groups regarding baseline data of computerized speech lab. /a/ (preoperatively)

\begin{tabular}{lccc}
\hline Variables & Groups & Mean \pm SD & $P$-value \\
\hline Jitter /a/ & Coblation & $2.47 \pm 1.61$ & 0.349 \\
& Microdebrider & $3.53 \pm 2.40$ & \\
& MLS & $3.91 \pm 2.64$ & \\
Shimmer /a/ & Coblation & $4.53 \pm 1.97$ & 0.071 \\
& Microdebrider & $8.21 \pm 5.05$ & \\
& MLS & $11.68 \pm 10.10$ & \\
N/H /a/ & Coblation & $0.21 \pm 0.20$ & 0.661 \\
& Microdebrider & $0.27 \pm 0.11$ & \\
FO /a/ & MLS & $0.23 \pm 0.13$ & \\
& Coblation & $260.04 \pm 113.43$ & $0.040^{*}$ \\
& Microdebrider & $206.18 \pm 54.35$ & \\
Highest FO /a/ & MLS & $163.83 \pm 58.05$ & \\
& Coblation & $304.26 \pm 138.06$ & 0.246 \\
& Microdebrider & $266.68 \pm 52.83$ & \\
& MLS & $227.57 \pm 89.18$ & \\
Lowest FO /a/ & Coblation & $226.79 \pm 94.90$ & $0.005^{*}$ \\
& Microdebrider & $147.08 \pm 70.56$ & \\
& MLS & $115.02 \pm 37.78$ & \\
\hline
\end{tabular}

MLS, microlaryngosurgical. ${ }^{*} P<0.05$, significant.

Table 4 Comparison between the three groups regarding baseline data of computerized speech lab. /i/ (preoperatively)

\begin{tabular}{llcc}
\hline Variables & Groups & Mean \pm SD & $P$-value \\
\hline Jitter /i/ & Coblation & $2.17 \pm 1.69$ & 0.248 \\
& Microdebrider & $2.67 \pm 1.80$ & \\
& MLS & $3.56 \pm 1.98$ & \\
Shimmer /i/ & Coblation & $4.04 \pm 1.60$ & $0.007^{*}$ \\
& Microdebrider & $5.58 \pm 2.13$ & \\
& MLS & $9.01 \pm 5.00$ & \\
N/H /i/ & Coblation & $0.21 \pm 0.19$ & 0.663 \\
& Microdebrider & $0.25 \pm 0.09$ & \\
FO /i/ & MLS & $0.25 \pm 0.17$ & \\
& Coblation & $261.30 \pm 118.10$ & $0.023^{*}$ \\
& Microdebrider & $220.97 \pm 49.08$ & \\
Highest FO /i/ & MLS & $161.26 \pm 31.77$ & \\
& Coblation & $301.17 \pm 143.31$ & 0.067 \\
& Microdebrider & $282.15 \pm 64.50$ & \\
Lowest FO /i/ & MLS & $202.99 \pm 49.51$ & \\
& Coblation & $226.20 \pm 103.57$ & $0.009^{*}$ \\
& Microdebrider & $185.49 \pm 57.87$ & \\
& MLS & $120.29 \pm 34.89$ &
\end{tabular}

MLS, microlaryngosurgical. ${ }^{\star} P<0.05$, significant.

(1) Group A: microlaryngosurgical

(a) $50 \%$ of patients of this group were recorded as normal (no roughness).

(b) $30 \%$ of patients of this group had mild roughness. 
Table 5 Comparison between the three groups regarding baseline data of computerized speech lab. /u/ (preoperatively)

\begin{tabular}{lccc}
\hline Variables & Groups & Mean \pm SD & $P$-value \\
\hline Jitter $/ \mathrm{u} /$ & Coblation & $2.22 \pm 1.38$ & 0.843 \\
& Microdebrider & $2.69 \pm 2.08$ & \\
& MLS & $2.36 \pm 1.95$ & \\
Shimmer /u/ & Coblation & $3.85 \pm 1.51$ & 0.076 \\
& Microdebrider & $6.17 \pm 3.22$ & \\
& MLS & $7.71 \pm 5.23$ & \\
$\mathrm{~N} / \mathrm{H} / \mathrm{u} /$ & Coblation & $19.00 \pm 59.37$ & 0.382 \\
& Microdebrider & $0.31 \pm 0.22$ & \\
FO /u/ & MLS & $0.71 \pm 0.07$ & \\
& Coblation & $262.68 \pm 116.19$ & $0.012^{\star}$ \\
& Microdebrider & $209.99 \pm 51.32$ & \\
Highest FO /u/ & MLS & $153.83 \pm 29.07$ & \\
& Coblation & $300.15 \pm 132.39$ & 0.297 \\
& Microdebrider & $282.34 \pm 138.50$ & \\
Lowest FO /u/ & MLS & $213.01 \pm 115.57$ & \\
& Coblation & $227.08 \pm 105.52$ & $0.005^{\star}$ \\
& Microdebrider & $162.11 \pm 66.55$ & \\
& MLS & $105.91 \pm 36.93$ & \\
\hline
\end{tabular}

MLS, microlaryngosurgical. * $P<0.05$, significant.

(c) $20 \%$ of patients of this group had still rough voice.

(2) Group B: microdebrider

(a) $50 \%$ of patients of this group were recorded as normal (no roughness).

(b) $50 \%$ of patients of this group had still rough voice.

(3) Group C: coblation

(a) $50 \%$ of patients of this group were recorded as normal (no roughness).

(b) $50 \%$ of patients of this group had still rough voice.

B: all the patients showed improvement of breathiness

(1) Group A: microlaryngosurgical

(a) $90 \%$ of patients of this group were recorded as normal (no breathiness).

(b) $10 \%$ of patients of this group had mild breathiness.

(2) Group B: microdebrider

(a) $70 \%$ of patients of this group were recorded as normal (no breathiness).

(b) $30 \%$ of patients of this group had mild breathiness.

(3) Group C: coblation

(a) $70 \%$ of patients of this group were recorded as normal (no breathiness).

(b) $30 \%$ of patients of this group had mild breathiness.

Acoustic analysis using computerized speech lab.

Results of our study showed marked reduction of jitter and shimmer\% with variable changes regarding other parameters; the following tables and graphs show these changes, and the significant statistical differences $(P<0.05)$.

Tables 12-14 show that no significant statistical differences are detected between the three groups.

Finally, all of the above revealed that no significant statistical differences were detected between the three groups of our study.

\section{Postoperative recovery and complications}

There was no difference between the three groups regarding smoothness of postoperative recovery and administration of analgesia. No significant complications were encountered in all groups.

\section{Discussion}

Various authors have reported vocal fold polyps to be the most common type of benign lesions of the larynx with preponderance in males. Hoarseness of voice is a common complaint in today's high-stressed life and describes terms such as dysphonia, aphonia, voice break and odynophonia and most commonly phonasthenia [7].

Voice therapy, or voice training, refers to a variety of nonsurgical techniques used to improve or modify the voice quality. The goal of voice therapy is to modify vocal behaviours to reduce laryngeal trauma. Typically, it involves vocal and physical exercises coupled with behaviour changes, including vocal hygiene, voice rest, muscle relaxation and respiratory support. Voice therapy is an effective method for improving voice quality and vocal performance in patients with nonorganic dysphonia and for treating many benign pathologic vocal fold findings, especially vocal fold nodules [8].

Failure of voice therapy to improve or alleviate vocal symptoms is the most common indication for the surgical removal of these benign lesions. Surgical removal with microsurgical instruments remains the mainstay of the therapy for laryngeal polyps, cysts and nodules [9].

Radiophonosurgery using radiofrequency opened up a new therapeutic approach for patients with benign superficial vocal fold lesions. It combines the advantages of both cold knife and laser phonosurgery, being easy, safe, precise and effective with excellent tactile and haemostatic properties [2]. 
In the practice of management of benign vocal fold lesions, cold knife instruments have been reported to be the safest and the most widely used with excellent results [10].

In this study, the aim of our work was to compare and investigate the efficacy and safety of some recent techniques (microdebrider and radiofrequency) in excision of benign vocal fold lesions and to assess the outcome of each technique; we compared the results of these recent techniques in laryngeal surgery with the classic MLS (cold knife), being the cornerstone in the management of benign vocal fold lesions as reported by Sulica and Behrman [10].

As regards the sex incidence, the male preponderance is similar to other studies, and vocal fold polyps were most common; this is in accordance with Dikkers et al. (1995) [11] who reported that vocal fold polyps are the most common form of benign vocal fold lesions.

\section{Preoperative baseline data}

Regarding auditory perceptual assessment of voice, no marked differences between the three groups were observed.

All patients had a rough voice with a certain grade of dysphonia ranging between 2 and 3, as shown in Table 2.
All patients of groups B and C had a breathy voice, being mostly large vocal fold polyps, and also $60 \%$ of patients of group A had a breathy voice. However, this type of assessment is subjective depending on the examiner for qualitative assessment of voice, and thus we used the computerized speech lab. for quantitative assessment.

There were no highly significant statistical differences between the three groups regarding preoperative baseline data; however, there were some significant differences that may be due to changes in the size of each lesion or differences between male and female patients, and these results are shown in Tables 3-5.

\section{Postoperative data}

The results of this study showed that the patients of all groups showed marked improvement regarding dysphonia and self-assessment of voice quality.

The auditory perceptual assessment using GRB scale showed improvement of vocal functions including grade of dysphonia (Table 6 and Charts 1-3), which indicated that $50 \%$ of patients of groups B and C and $40 \%$ of patients of group A reported as grade 0 dysphonia (normal) 2 weeks postoperatively before starting voice therapy sessions.

Table 6 Comparison between the three groups regarding the grade of dysphonia (postoperative)

\begin{tabular}{lcccc}
\hline Grade (postoperatively) & \multicolumn{3}{c}{ Groups $[n(\%)]$} & \multicolumn{2}{c}{ Total } \\
\cline { 2 - 4 } & Coblation & Microdebrider & $4(40.0)$ & $14(46.7)$ \\
0 & $5(50.0)$ & $5(50.0)$ & $6(60.0)$ & $15(50.0)$ \\
1 & $(40.0)$ & $5(50.0)$ & $0(0.0)$ & $1(3.3)$ \\
2 & $1(10.0)$ & $0(0.0)$ & $10(100.0)$ & $30(100.0)$ \\
\hline
\end{tabular}

MLS, microlaryngosurgical. $P=0.637 . P<0.05$, significant.

\section{Chart 1}

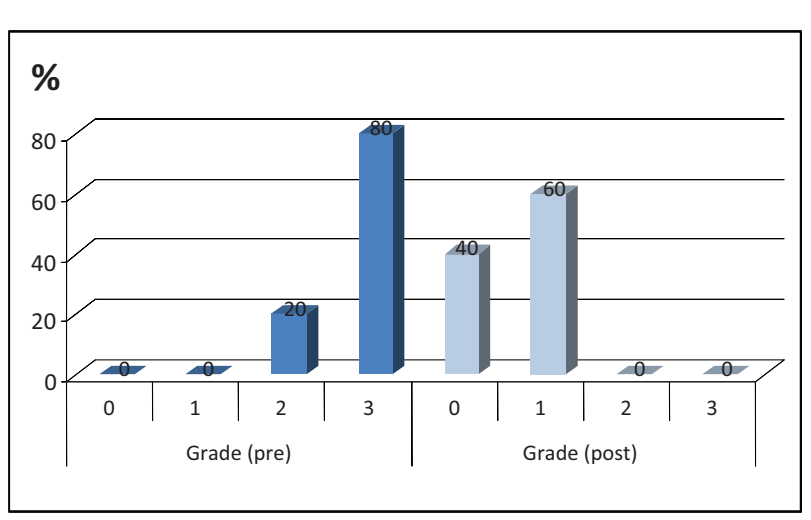

Comparison between preoperative and postoperative grade of dysphonia in group A (microlaryngosurgical).
Chart 2

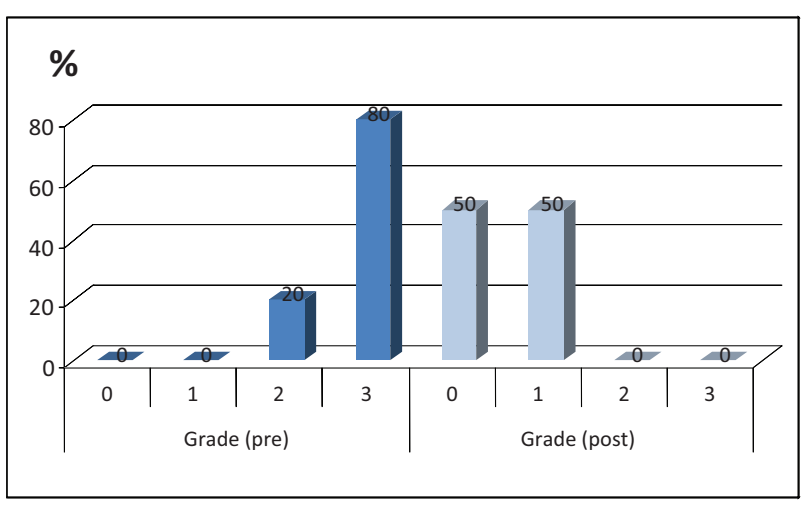

Comparison between preoperative and postoperative grade of dysphonia in group B (microdebrider). 
Improvement of roughness is shown in Table 7 and Charts $4-6$, which indicated that $50 \%$ of patients of three groups reported to have a normal voice (no roughness) 2 weeks postoperatively before starting voice therapy sessions.

Improvement of breathiness is shown in Table 8 and Charts 7-9, which indicated that $90 \%$ of patients of group A and $70 \%$ of patients of groups B and C reported to have no breathiness 2 weeks postoperatively before starting voice therapy sessions.

No marked differences were detected between the three groups regarding improvement of vocal functions (detected by auditory perceptual assessment), which means that the recent techniques we used in our study give nearly the same results of classic MLS regarding qualitative assessment of vocal functions.Acoustic analysis using CSL showed marked improvement of vocal

Chart 3

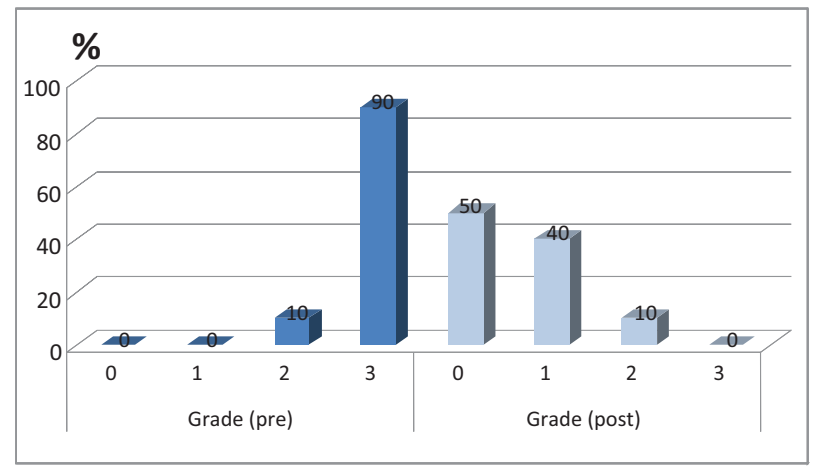

Comparison between preoperative and postoperative grade of dysphonia in group $\mathrm{C}$ (coblation). functions of all patients of the three groups, proved by marked reduction in jitter and shimmer\% accompanied by reduction harmonic to noise ratio $(\mathrm{H} / \mathrm{N})$ ratio with marked changes of fundamental frequency and highest and lowest FO.

\section{Chart 4}

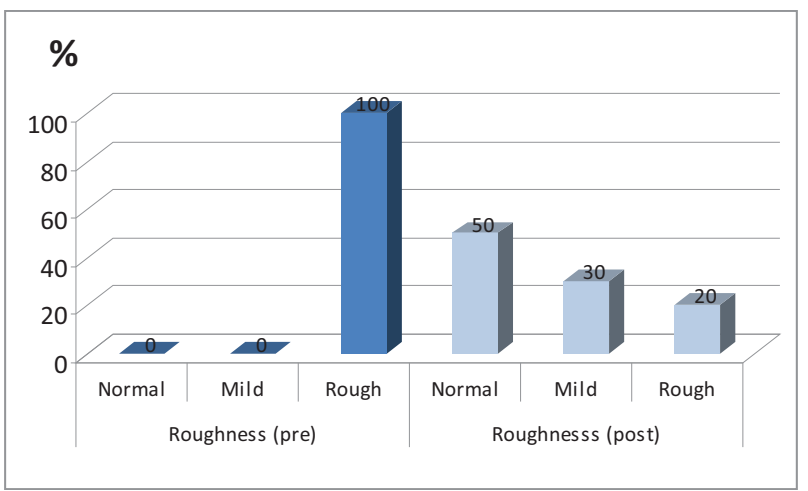

Comparison between preoperative and postoperative grade of roughness in group A (microlaryngosurgical).

\section{Chart 5}

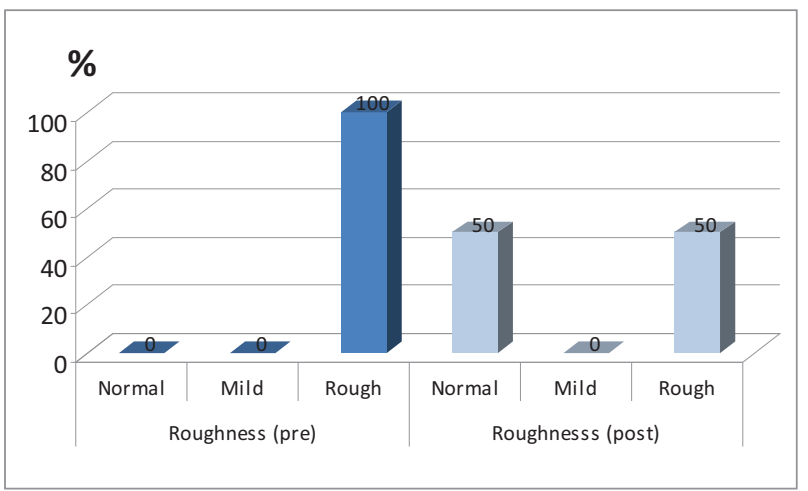

Comparison between preoperative and postoperative grade of roughness in group B (microdebrider).

Table 7 Comparison between the three groups regarding the grade of roughness (postoperatively)

\begin{tabular}{lcccc}
\hline Roughness (postoperatively) & \multicolumn{3}{c}{ Groups $[n(\%)]$} & \multicolumn{1}{c}{ MLS } \\
\cline { 2 - 4 } & Coblation & Microdebrider & $5(50.0)$ & $15(50.0)$ \\
\hline Normal & $5(50.0)$ & $5(50.0)$ & $3(30.0)$ & $3(10.0)$ \\
Mild & $0(0.0)$ & $5(0.0)$ & $2(20.0)$ & $12(40.0)$ \\
Rough & $5(50.0)$ & $5(50.0)$ & $10(100.0)$ & $30(100.0)$ \\
Total & $10(100.0)$ & $10(100.0)$ & &
\end{tabular}

MLS, microlaryngosurgical. $P=0.112 . P<0.05$, significant.

Table 8 Comparison between the three groups regarding the grade of breathiness (postoperatively)

\begin{tabular}{|c|c|c|c|c|}
\hline \multirow[t]{2}{*}{ Breathiness (postoperatively) } & \multicolumn{3}{|c|}{ Groups $[n(\%)]$} & \multirow[t]{2}{*}{ Total } \\
\hline & Coblation & Microdebrider & MLS & \\
\hline Normal & $7(70.0)$ & $7(70.0)$ & $9(90.0)$ & $23(76.7)$ \\
\hline Mild & $3(30.0)$ & $3(30.0)$ & $1(10.0)$ & $7(24.3)$ \\
\hline Breathy & $0(0)$ & $0(0)$ & $0(0)$ & $0(0)$ \\
\hline Total & $10(100.0)$ & $10(100.0)$ & $10(100.0)$ & $30(100.0)$ \\
\hline
\end{tabular}

MLS, microlaryngosurgical. $P<0.05$, significant. $P=0.431$. 


\section{Chart 6}

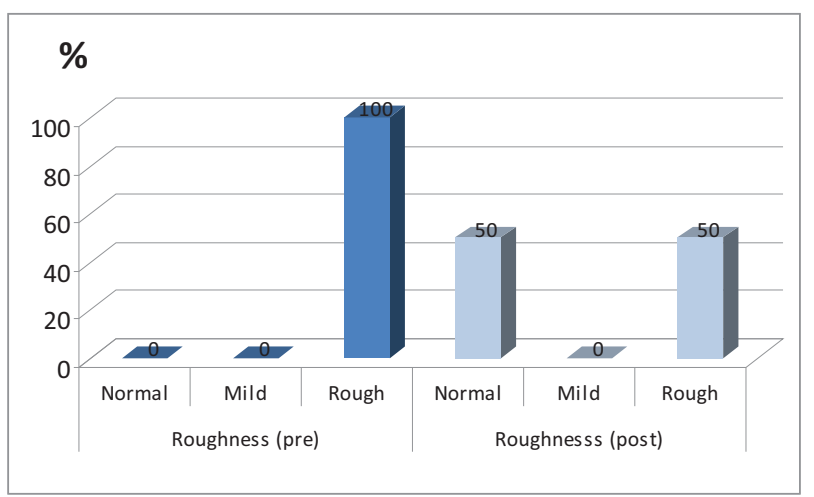

Comparison between preoperative and postoperative grade of roughness in group $\mathrm{C}$ (coblation).

\section{Chart 7}

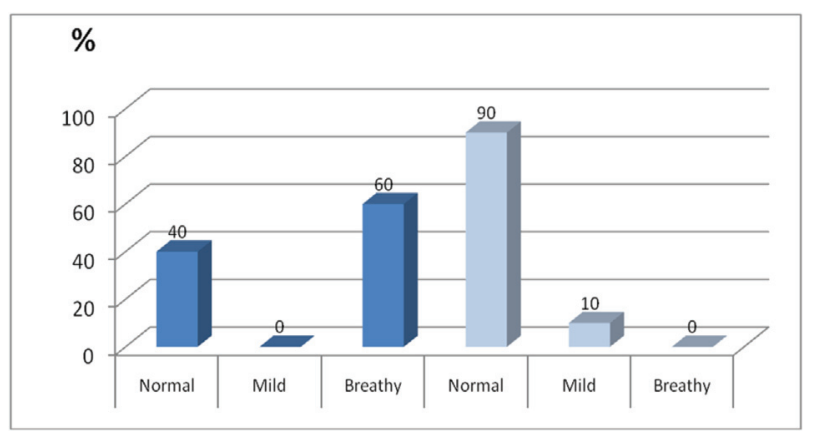

Comparison between preoperative and postoperative grade of breathiness in group A (microlaryngosurgical).

\section{Chart 8}

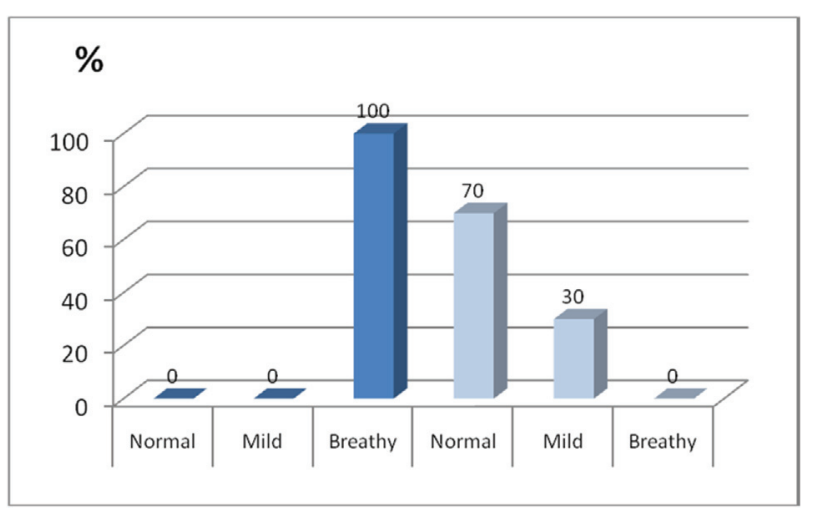

Comparison between preoperative and postoperative grade of breathiness in group B (microdebrider)

These results are shown in Tables 9-11 and Charts 10-12.

No significant statistical differences were noted between the three groups (Tables 12-14), and this means that the results of new techniques used (microdebrider and radiofrequency) are nearly equal
Chart 9

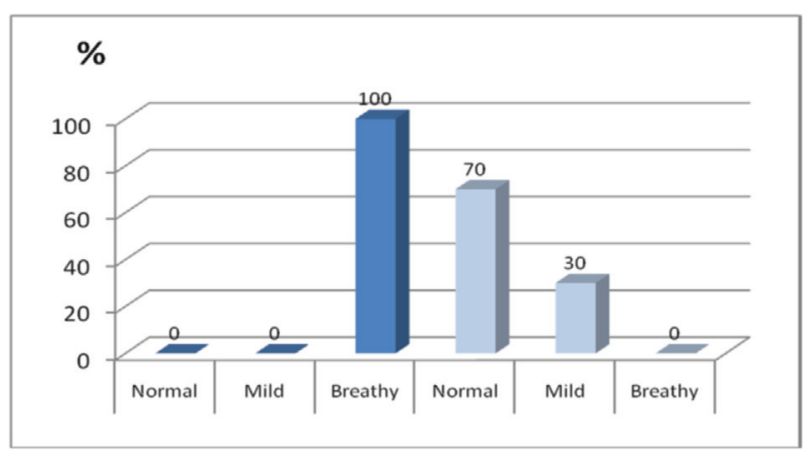

Comparison between preoperative and postoperative grade of breathiness in group C (coblation).

\section{Chart 10}
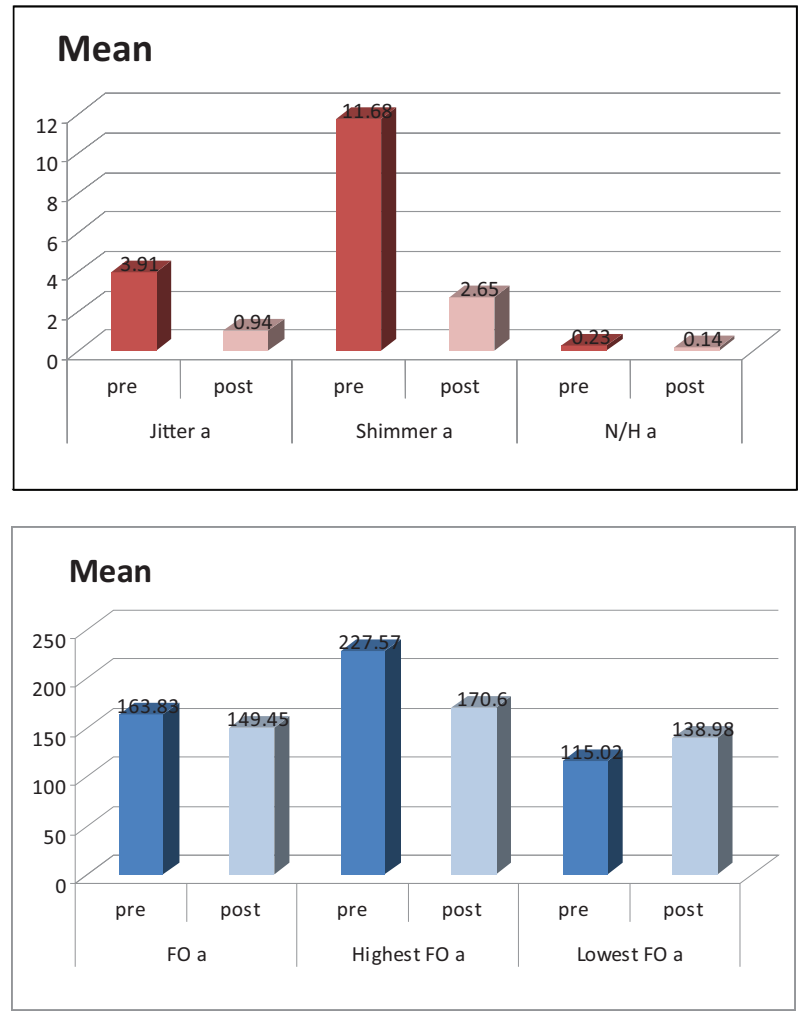

Comparison between preoperative and postoperative data of the patients of group A (microlaryngosurgical): /a/.

to those of classic MLS techniques regarding also quantitative assessment of vocal functions; this matches with the results reached by Ragab et al. [2].

No marked differences were detected between the three groups regarding smoothness of postoperative period, and no complications encountered within all groups

We found that radiofrequency has an excellent haemostatic action that helped us especially in case of large-sized vocal fold polyps with high 
Table 9 Comparison between preoperative and postoperative data of the patients of group A (microlaryngosurgical.)

\begin{tabular}{|c|c|c|}
\hline & Mean \pm SD & $P$-value \\
\hline \multicolumn{3}{|l|}{ Jitter /a/ } \\
\hline Preoperative & $3.91 \pm 2.64$ & $0.006^{*}$ \\
\hline Postoperative & $0.94 \pm 0.55$ & \\
\hline \multicolumn{3}{|l|}{ Shimmer /a/ } \\
\hline Preoperative & $11.68 \pm 10.10$ & $0.013^{*}$ \\
\hline Postoperative & $2.65 \pm 1.60$ & \\
\hline \multicolumn{3}{|l|}{$\mathrm{N} / \mathrm{H} / \mathrm{a} /$} \\
\hline Preoperative & $0.23 \pm 0.13$ & 0.051 \\
\hline Postoperative & $0.14 \pm 0.03$ & \\
\hline \multicolumn{3}{|l|}{$\mathrm{FO} / \mathrm{a} /$} \\
\hline Preoperative & $163.83 \pm 58.05$ & 0.275 \\
\hline Postoperative & $149.45 \pm 37.26$ & \\
\hline \multicolumn{3}{|l|}{ Highest FO /a/ } \\
\hline Preoperative & $227.57 \pm 89.18$ & $0.037^{*}$ \\
\hline Postoperative & $170.60 \pm 46.43$ & \\
\hline \multicolumn{3}{|l|}{ Lowest FO /a/ } \\
\hline Preoperative & $115.02 \pm 37.78$ & 0.223 \\
\hline Postoperative & $138.98 \pm 34.64$ & \\
\hline \multicolumn{3}{|l|}{ Jitter /i/ } \\
\hline Preoperative & $3.56 \pm 1.98$ & $0.009^{*}$ \\
\hline Postoperative & $1.54 \pm 1.07$ & \\
\hline \multicolumn{3}{|l|}{ Shimmer /i/ } \\
\hline Preoperative & $9.01 \pm 5.00$ & $0.001^{*}$ \\
\hline Postoperative & $2.99 \pm 2.03$ & \\
\hline \multicolumn{3}{|l|}{$\mathrm{N} / \mathrm{H} / \mathrm{i} /$} \\
\hline Preoperative & $0.25 \pm 0.17$ & 0.070 \\
\hline Postoperative & $0.15 \pm 0.03$ & \\
\hline \multicolumn{3}{|l|}{$\mathrm{FO} / \mathrm{i} /$} \\
\hline Preoperative & $161.26 \pm 31.77$ & 0.162 \\
\hline Postoperative & $151.64 \pm 35.79$ & \\
\hline \multicolumn{3}{|l|}{ Highest FO /i/ } \\
\hline Preoperative & $202.99 \pm 49.51$ & $0.001^{*}$ \\
\hline Postoperative & $164.28 \pm 36.34$ & \\
\hline \multicolumn{3}{|l|}{ Lowest FO /i/ } \\
\hline Preoperative & $120.29 \pm 34.89$ & 0.206 \\
\hline Postoperative & $141.34 \pm 33.20$ & \\
\hline \multicolumn{3}{|l|}{ Jitter /u/ } \\
\hline Preoperative & $2.36 \pm 1.95$ & 0.059 \\
\hline Postoperative & $1.12 \pm 0.61$ & \\
\hline \multicolumn{3}{|l|}{ Shimmer /u/ } \\
\hline Preoperative & $7.71 \pm 5.23$ & $0.005^{\star}$ \\
\hline Postoperative & $2.80 \pm 1.30$ & \\
\hline \multicolumn{3}{|l|}{$\mathrm{N} / \mathrm{H} / \mathrm{u} /$} \\
\hline Preoperative & $0.17 \pm 0.07$ & 0.796 \\
\hline Postoperative & $0.19 \pm 0.17$ & \\
\hline \multicolumn{3}{|l|}{$\mathrm{FO} / \mathrm{u} /$} \\
\hline Preoperative & $153.83 \pm 29.07$ & 0.803 \\
\hline Postoperative & $157.56 \pm 36.70$ & \\
\hline \multicolumn{3}{|l|}{ Highest FO /u/ } \\
\hline Preoperative & $213.01 \pm 115.57$ & 0.135 \\
\hline Postoperative & $168.81 \pm 35.24$ & \\
\hline \multicolumn{3}{|l|}{ Lowest FO /u/ } \\
\hline Preoperative & $105.91 \pm 36.93$ & 0.052 \\
\hline Postoperative & $147.39 \pm 39.45$ & \\
\hline
\end{tabular}

${ }^{\star} P<0.05$, significant.
Table 10 Comparison between preoperative and postoperative data of the patients of group B (microdebrider)

\begin{tabular}{lll}
\hline & Mean \pm SD & $P$-value \\
\hline Jitter /a/ & & \\
Preoperative & $3.53 \pm 2.40$ & $0.011^{*}$ \\
Postoperative & $1.51 \pm 1.25$ & \\
Shimmer /a/ & & $0.023^{*}$ \\
Preoperative & $8.21 \pm 5.05$ & \\
Postoperative & $3.17 \pm 2.00$ & $0.003^{*}$ \\
N/H /a/ & & \\
Preoperative & $0.27 \pm 0.11$ & \\
Postoperative & $0.13 \pm 0.01$ &
\end{tabular}

$\mathrm{FO} / \mathrm{a} /$

$\begin{array}{ccc}\text { Preoperative } & 206.18 \pm 54.35 & 0.369 \\ \text { Postoperative } & 194.06 \pm 55.56 & \\ \text { Highest FO /a/ } & & 0.009^{*} \\ \text { Preoperative } & 266.68 \pm 52.83 & \\ \text { Postoperative } & 206.66 \pm 62.48 & \\ \text { Lowest FO /a/ } & & 0.144 \\ \text { Preoperative } & 147.08 \pm 70.56 & \end{array}$

Postoperative $\quad 179.50 \pm 51.70$

Jitter /i/

$\begin{array}{lll}\text { Preoperative } & 2.67 \pm 1.80 & 0.025^{*} \\ \text { Postoperative } & 1.28 \pm 0.91 & \\ \text { Shimmer /i/ } & & \\ \text { Preoperative } & 5.58 \pm 2.13 & 0.001^{*} \\ \text { Postoperative } & 2.93 \pm 1.47 & \\ \text { N/H /i/ } & & \\ \text { Preoperative } & 0.25 \pm 0.09 & 0.004^{*} \\ \text { Postoperative } & 0.13 \pm 0.02 & \end{array}$

$\mathrm{FO} / \mathrm{i} /$

$\begin{array}{ccc}\text { Preoperative } & 220.97 \pm 49.08 & 0.412 \\ \text { Postoperative } & 206.57 \pm 71.95 & \\ \text { Highest FO /i/ } & & \\ \text { Preoperative } & 282.15 \pm 64.50 & 0.088\end{array}$

$\begin{array}{lcl}\text { Postoperative } & 223.17 \pm 83.55 & \\ \text { Lowest FO /i/ } & & \\ \text { Preoperative } & 185.49 \pm 57.87 & 0.764\end{array}$

Postoperative $\quad 189.51 \pm 58.13$ Jitter /u/

$\begin{array}{lll}\text { Preoperative } & 2.69 \pm 2.08 & 0.016^{*}\end{array}$

Postoperative $\quad 0.99 \pm 0.62$

$\begin{array}{lll}\text { Shimmer } / \mathrm{u} / & & \\ \text { Preoperative } & 6.17 \pm 3.22 & 009^{*}\end{array}$

$\begin{array}{ll}\text { Postoperative } & 2.76 \pm 1.27\end{array}$

$0.31 \pm 0.22 \quad 0.034^{*}$

$\begin{array}{lll}\text { Preoperative } & 0.31 \pm 0.22 & 0.034^{*} \\ \text { Postoperative } & 0.13 \pm 0.01 & \end{array}$

$\mathrm{FO} / \mathrm{u} /$

\begin{tabular}{lcc} 
Preoperative & $209.99 \pm 51.32$ & 0.120 \\
Postoperative & $191.72 \pm 53.49$ & \\
Highest FO /u/ & & \\
Preoperative & $282.34 \pm 138.50$ & 0.111 \\
Postoperative & $208.02 \pm 67.82$ & \\
Lowest FO /u/ & & \\
Preoperative & $162.11 \pm 66.55$ & 0.389 \\
Postoperative & $180.85 \pm 49.40$ & \\
\hline
\end{tabular}

${ }^{*} P<0.05$, significant. 
Table 11 Comparison between preoperative and postoperative data of the patients of group C (coblation)

\begin{tabular}{|c|c|c|}
\hline & Mean \pm SD & $P$-value \\
\hline \multicolumn{3}{|l|}{ Jitter /a/ } \\
\hline Preoperative & $2.47 \pm 1.61$ & 0.088 \\
\hline Postoperative & $1.53 \pm 1.59$ & \\
\hline \multicolumn{3}{|l|}{ Shimmer /a/ } \\
\hline Preoperative & $4.53 \pm 1.97$ & 0.985 \\
\hline Postoperative & $4.50 \pm 4.39$ & \\
\hline \multicolumn{3}{|l|}{$\mathrm{N} / \mathrm{H} / \mathrm{a} /$} \\
\hline Preoperative & $0.21 \pm 0.21$ & 0.816 \\
\hline Postoperative & $0.19 \pm 0.13$ & \\
\hline \multicolumn{3}{|l|}{$\mathrm{FO} / \mathrm{a} /$} \\
\hline Preoperative & $260.04 \pm 113.4$ & $0.001^{*}$ \\
\hline Postoperative & $198.88 \pm 79.19$ & \\
\hline \multicolumn{3}{|l|}{ Highest FO /a/ } \\
\hline Preoperative & $304.26 \pm 138.06$ & $0.004^{*}$ \\
\hline Postoperative & $237.06 \pm 103.76$ & \\
\hline \multicolumn{3}{|l|}{ Lowest FO /a/ } \\
\hline Preoperative & $226.79 \pm 94.90$ & $0.027^{*}$ \\
\hline Postoperative & $149.22 \pm 50.46$ & \\
\hline \multicolumn{3}{|l|}{ Jitter /i/ } \\
\hline Preoperative & $2.17 \pm 1.69$ & 0.867 \\
\hline Postoperative & $2.10 \pm 2.36$ & \\
\hline \multicolumn{3}{|l|}{ Shimmer /i/ } \\
\hline Preoperative & $4.04 \pm 1.60$ & 0.465 \\
\hline Postoperative & $5.82 \pm 8.32$ & \\
\hline \multicolumn{3}{|l|}{$\mathrm{N} / \mathrm{H} / \mathrm{i} /$} \\
\hline Preoperative & $0.21 \pm 0.19$ & 0.915 \\
\hline Postoperative & $0.18 \pm 0.12$ & \\
\hline \multicolumn{3}{|l|}{ FO /i/ } \\
\hline Preoperative & $261.30 \pm 118.10$ & $0.012^{*}$ \\
\hline Postoperative & $182.40 \pm 56.36$ & \\
\hline \multicolumn{3}{|l|}{ Highest FO /i/ } \\
\hline Preoperative & $301.17 \pm 143.31$ & $0.005^{*}$ \\
\hline Postoperative & $220.99 \pm 98.46$ & \\
\hline \multicolumn{3}{|l|}{ Lowest FO /i/ } \\
\hline Preoperative & $226.20 \pm 103.57$ & 0.066 \\
\hline Postoperative & $140.17 \pm 50.63$ & \\
\hline \multicolumn{3}{|l|}{ Jitter /u/ } \\
\hline Preoperative & $2.22 \pm 1.38$ & 0.650 \\
\hline Postoperative & $1.98 \pm 2.19$ & \\
\hline \multicolumn{3}{|l|}{ Shimmer /u/ } \\
\hline Preoperative & $3.85 \pm 1.51$ & 0.773 \\
\hline Postoperative & $4.40 \pm 5.86$ & \\
\hline \multicolumn{3}{|l|}{$\mathrm{N} / \mathrm{H} / \mathrm{u} /$} \\
\hline Preoperative & $19.00 \pm 59.37$ & 0.342 \\
\hline Postoperative & $0.18 \pm 0.13$ & \\
\hline \multicolumn{3}{|l|}{$\mathrm{FO} / \mathrm{u} /$} \\
\hline Preoperative & $262.68 \pm 116.19$ & $0.006^{*}$ \\
\hline Postoperative & $202.80 \pm 86.01$ & \\
\hline \multicolumn{3}{|l|}{ Highest FO /u/ } \\
\hline Preoperative & $300.15 \pm 132.39$ & $0.004^{*}$ \\
\hline Postoperative & $245.71 \pm 102.69$ & \\
\hline \multicolumn{3}{|l|}{ Lowest FO /u/ } \\
\hline Preoperative & $227.08 \pm 105.52$ & $0.039^{*}$ \\
\hline Postoperative & $167.68 \pm 91.62$ & \\
\hline
\end{tabular}

${ }^{\star} P<0.05$, significant.
Chart 11
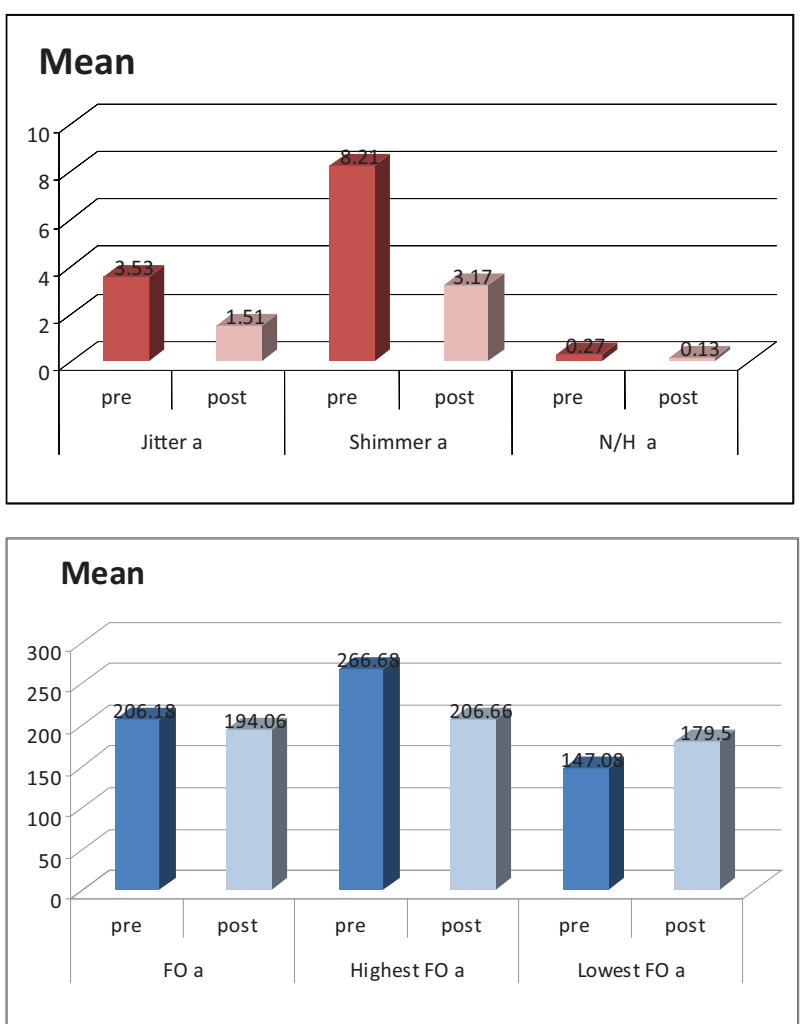

Comparison between preoperative and postoperative data of the patients of group B (microdebrider): /a/.

\section{Chart 12}
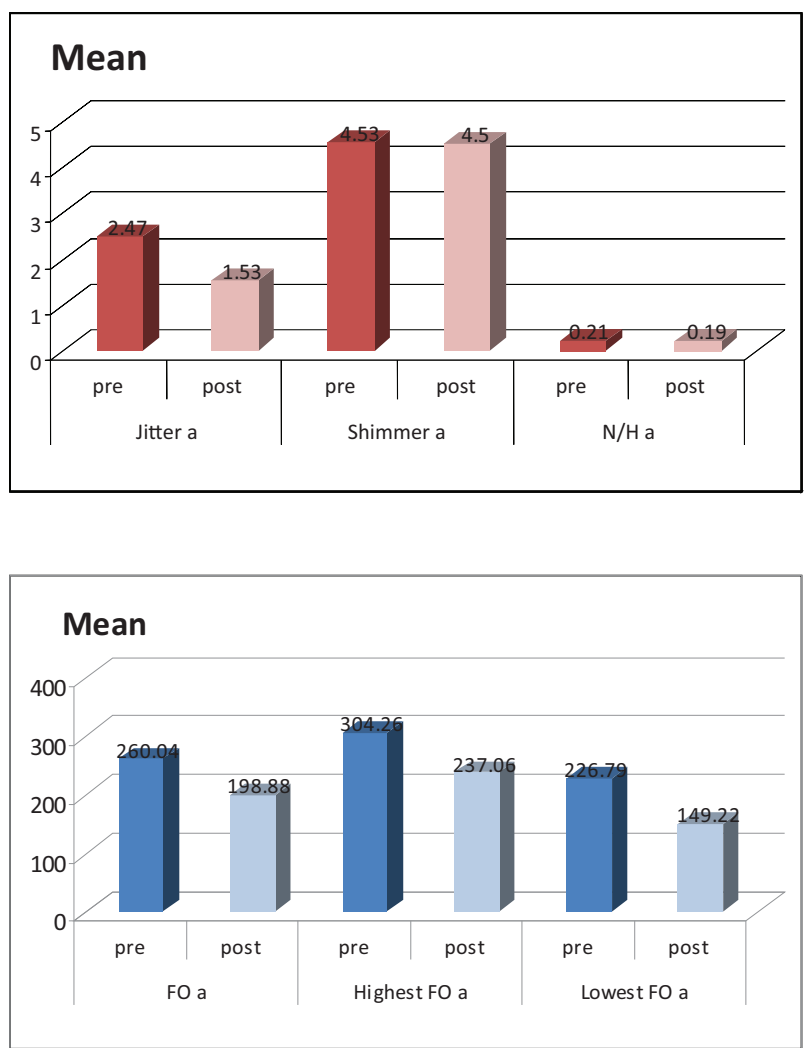

Comparison between preoperative and postoperative data of the patients of group C (coblation): /a/. 
Table 12 Comparison between groups of the study regarding improvement of different variables after intervention /a/

\begin{tabular}{lccc}
\hline Variables & Groups & Mean \pm SD & $P$-value \\
\hline Jitter /a/ & Coblation & $1.59 \pm 1.53$ & 0.474 \\
& Microdebrider & $1.51 \pm 1.25$ & \\
& MLS & $0.94 \pm 0.55$ & \\
Shimmer /a/ & Coblation & $4.50 \pm 4.39$ & 0.363 \\
& Microdebrider & $3.17 \pm 2.00$ & \\
& MLS & $2.65 \pm 1.60$ & \\
N/H /a/ & Coblation & $0.19 \pm 0.13$ & 0.196 \\
& Microdebrider & $0.13 \pm 0.01$ & \\
FO /a/ & MLS & $0.94 \pm 0.55$ & \\
& Coblation & $198.88 \pm 79.19$ & 0.145 \\
& Microdebrider & $194.06 \pm 55.56$ & \\
Highest FO /a/ & MLS & $149.45 \pm 37.26$ & \\
& Coblation & $237.06 \pm 103.76$ & 0.159 \\
& Microdebrider & $206.66 \pm 62.48$ & \\
& MLS & $170.60 \pm 46.43$ & \\
Lowest FO /a/ & Coblation & $149.22 \pm 50.46$ & 0.145 \\
& Microdebrider & $179.50 \pm 51.70$ & \\
& MLS & $138.98 \pm 34.64$ & \\
\hline
\end{tabular}

MLS, microlaryngosurgical. No significant statistical differences were detected between the three groups of our study.

Table 13 Comparison between groups of the study regarding different variables after intervention /i/

\begin{tabular}{lccc}
\hline Variables & Groups & Mean \pm SD & $P$-value \\
\hline Jitter /i/ & Coblation & $2.10 \pm 2.36$ & 0.505 \\
& Microdebrider & $1.28 \pm 0.91$ & \\
Shimmer /i/ & MLS & $1.54 \pm 1.07$ & \\
& Coblation & $5.82 \pm 8.32$ & 0.352 \\
& Microdebrider & $2.93 \pm 1.47$ & \\
$\mathrm{~N} / \mathrm{H} / \mathrm{i} /$ & MLS & $2.99 \pm 2.03$ & \\
& Coblation & $0.18 \pm 0.12$ & 0.264 \\
& Microdebrider & $0.13 \pm 0.02$ & \\
FO /i/ & MLS & $0.15 \pm 0.03$ & \\
& Coblation & $182.40 \pm 56.36$ & 0.114 \\
& Microdebrider & $206.57 \pm 71.95$ & \\
Highest FO /i/ & MLS & $151.64 \pm 35.79$ & \\
& Coblation & $220.99 \pm 98.46$ & 0.175 \\
& Microdebrider & $223.17 \pm 83.55$ & \\
& MLS & $164.28 \pm 36.34$ & \\
Lowest FO /i/ & Coblation & $140.17 \pm 50.63$ & $0.049^{*}$ \\
& Microdebrider & $189.51 \pm 58.13$ & \\
& MLS & $141.34 \pm 33.20$ & \\
\hline
\end{tabular}

MLS, microlaryngosurgical. Apart from the last variable (lowest FO) /i/, no significant statistical differences were detected between the three groups of our study. ${ }^{*} P<0.05$, significant.

vascularity, and this leads to relatively shorter operative time with avoidance of fire risk, associated with improved access to the anterior commissure lesions, as it has a long handle that made manipulations of these lesions much easier and curved to allow better visualization.

However, the tip of the laryngeal handle of the radiofrequency device used in this study was (to
Table 14 Comparison between groups of the study regarding different variables after intervention / $u /$

\begin{tabular}{lccc}
\hline Variables & Groups & Mean \pm SD & $P$-value \\
\hline Jitter /u/ & Coblation & $1.98 \pm 2.19$ & 0.230 \\
& Microdebrider & $0.99 \pm 0.62$ & \\
& MLS & $1.12 \pm 0.61$ & \\
Shimmer /u/ & Coblation & $4.40 \pm 5.86$ & 0.510 \\
& Microdebrider & $2.76 \pm 1.27$ & \\
& MLS & $2.80 \pm 1.30$ & \\
$\mathrm{~N} / \mathrm{H} / \mathrm{u} /$ & Coblation & $0.18 \pm 0.13$ & 0.513 \\
& Microdebrider & $0.13 \pm 0.01$ & \\
FO /u/ & MLS & $0.19 \pm 0.17$ & \\
& Coblation & $202.80 \pm 86.01$ & 0.255 \\
& Microdebrider & $191.72 \pm 53.49$ & \\
Highest FO /u/ & MLS & $157.56 \pm 36.70$ & \\
& Coblation & $245.71 \pm 102.69$ & 0.085 \\
& Microdebrider & $208.02 \pm 67.82$ & \\
& MLS & $168.81 \pm 35.24$ & \\
Lowest FO /u/ & Coblation & $167.68 \pm 91.62$ & 0.511 \\
& Microdebrider & $180.85 \pm 49.40$ & \\
& MLS & $147.39 \pm 39.45$ & \\
\hline
\end{tabular}

MLS, microlaryngosurgical.

Figure 3

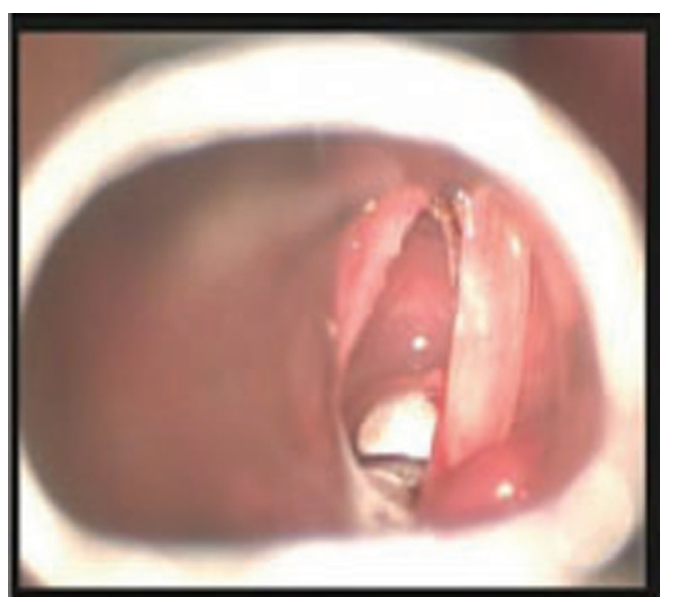

Injury of the left vocal fold after excision of the right vocal fold polyp (case from this study).

some extent) large and bulky, which may cause injury of the opposite fold if not used cautiously (Fig. 3).

However, the healing process was satisfactory, and this is indicated by the postoperative picture of the same patient in Fig. 4.

Regarding microdebrider, we found it to be of great value also with large vocal fold lesions, but the haemostatic function of radiofrequency is much better; also, it has a long handle facilitating access to the anterior commisure lesions. 
Figure 4

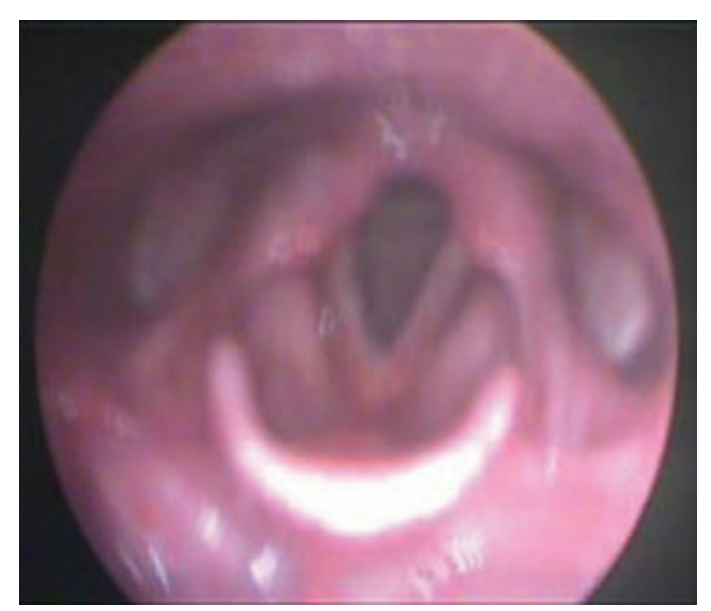

Postoperative view of the same patients (2 weeks postoperatively).

The suction component of the system allows the careful removal of abnormal tissues without injury of the underlying vocal ligament for more better voice outcome and less postoperative vocal fold scarring.

\section{Conclusion}

Classic MLS (cold knife) remains the main standard method for the treatment of benign vocal fold lesions, and the new techniques discussed in our study give nearly similar results compared with it; further research is needed to get more benefits of them and to widen the range of treatment modalities of these lesions, as well as introducing these recent techniques in the management of also malignant laryngeal lesions for laryngeal preservation and better voice outcome.

\section{Future and controversies}

Undoubtedly, the debate over ideal surgical techniques, instrumentation, and therapeutic regimens will continue as more data become available. Further research of bioimplantable materials will ideally render the potentially disastrous vocal complications of phonosurgery, such as scarring and loss of vibratory capacity, easier to treat.

\section{Financial support and sponsorship \\ Nil.}

\section{Conflicts of interest}

There are no conflicts of interest.

\section{References}

1 Cipriani NA, Martin DE, Corey JP, Portugal L, Caballero N, Lester R, et al. The clinicopathologic spectrum of benign mass lesions of the vocal fold due to vocal abuse. Int J Surg Pathol 2011; 19:583-587.

2 Ragab SM, EL Sheikh MN, Saafan ME, EL Sherif SG. The radiophonosurgery of benign superficial vocal fold lesions. J Laryngol Otol 2005; 119:961-966.

3 Johns MM. Update on the etiology, diagnosis, and treatment of vocal fold nodules, polyps, and cysts. Curr Opin Otolaryngol Head Neck Surg 2003; 11:456-461.

4 Beham AW, Puellmann K, Laird R, Fuchs T, Streich R, Breysach C, et al. A TNF-regulated recombinatorial macrophage immune receptor implicated in granuloma formation in tuberculosis. PLoS Pathog 2011; 7:e1002375.

5 Kuhn J, Toohill RJ, Ulualp SO, Kulpa J, Hofmann C, Arndorfer R, Shaker R. Pharyngeal acid reflux events in patients with vocal cord nodules. Laryngoscope 1998; 108(Part 1):1146-1149.

6 Reed AL, Flint P. Emerging role of powered instrumentation in airway surgery. Curr Opin Otolaryngol Head Neck Surg 2001; 9:387-392.

7 Hegde MC, Kamath MP, Bhojwani K, Peter R, Babu PR. Benign lesions of the larynx - a clinical study. Indian J Otolaryngol Head Neck Surg 2005; 57:35-38.

8 Ruotsalainen J, Sellman J, Lehto L, Verbeek J. Systematic review of the treatment of functional dysphonia and prevention of voice disorders. Otolaryngol Head Neck Surg 2008; 138:557-565.

9 Chagnon F, Stone RE Jr. Nodules and polyps. In: Brown WS, Vinson DP, Carry MA, editors. Organic voice disorders: assessment and treatment. San Diego: Singular Pub. Group; 1996; 57-62.

10 Sulica L, Behrman A. Management of benign vocal fold lesions: a survey of current opinion and practice. Ann Otol Rhinol Laryngol 2003; 112:827-833

11 Dikkers FG, Nikkels PG. Benign lesions of the vocal folds: histopathology and phonotrauma. Ann Otol Rhinol Laryngol 1995; 104 (Part 1):698-703. 